\title{
External Database Sebagai Media Integrasi Sistem Informasi Akademik dengan E-Learning
}

\author{
Muhammad Bunyamin ${ }^{1}$ Ahmad Syazili
}

\author{
Program Studi Sistem Informasi \\ Universitas Bina Darma \\ email : muhammad.bunyamin@ binadarma.ac.id ${ }^{1}$ syazili@binadarma.ac.id ${ }^{2}$ \\ J1. A. Yani No. 3, Palembang 30264, Indonesia
}

\begin{abstract}
Abstrak
Universitas Bina Darma Palembang merupakan salah satu Perguruan Tinggi Swasta yang memiliki banyak fakultas dan program studi. Untuk mengelola data akademik seperti penjadwalan, matakuliah, krs dan khs Universitas Bina Darma suda menggunakan Sistem Informasi Akademik yang sudah terintegrasi. Untuk mendukung proses belajar mengajar Universitas Bina Darma juga telah menggunakan Learning Management System (LMS) berbasis Moodle. Selama ini proses pengiriman data user, kelas, dan peserta kelas dilakukan dengan membuat program transfer data yang akan mentransfer data dari SIA ke Moodle. Permasalahan yang timbul adalah pertama jika ada perubahan data user seperti password dan lain sebagainya pada pertengahan semester maka tidak bisa secara otomatis mensikron dari SIA ke Moodle, sama halnya dengan perubahan data pengajar atau peserta kelas pada pertengahan semester harus dilakukan secara manual pada moodle, kedua riwayat peserta kelas dan pengajarnyapun terhapus setiap semester, karena program tersebut mengosongkan data kelas dan pesertanya setiap semester, hal ini menyebabkan dosen harus membackup dan mengupload ulang materi dan tugas nya setiap semester. Mengatasi hal tersebut dengan metode action research penulis membuat penelitian "External Database Sebagai Media Integrasi Sistem Informasi Akademik dengan Elaerning" sebagai solusinya. Penggunaan fitur External Database mengintegrasikan SIA dengan Moodle secara realtime, dan juga bisa mempertahankan riwayat mengajar dosen dan peserta kelas.
\end{abstract}

Kata kunci : E-Learning, SIA, External Database, Integrasi

\section{PENDAHULUAN}

Teknologi informasi dalam perkembanganya sangat dibutuhkan untuk membantu sebuah proses yang dilakukan oleh manusia. Teknologi informasi tersebut berguna untuk meningkatkan kualitas suatu organisasi yang berkembang di masyarakat.

Sistem informasi Akademik (SIA) dan el-learning merupakan bagian penting dari layanan IT yang tersedia di Univeristas Bina Darma. Kedua sistem tersebut sudah lama digunakan dan menyimpan dan memproses data yang sangat banyak. Selama ini kedua sistem tersebut merupakan sistem yang paling sering di akses baik oleh mahasiswa maupun oleh dosen di kalangan Universitas Bina Darma. Sistem informasi akademik merujuk pada seperangkat sistem dan aktivitas yang digunakan untuk menata, memproses, dan menggunakan informasi sebagai sumber dalam organisasi (Sprange \& Carlson, 1982). Adapun keluaran berupa informasi yang dihasilkan oleh sistem ini akan mensuplai informasi kepada para pimpinan atau pembuat 
keputusan yang 47 Jurnal Penelitian Pendidikan Vol. 12 No. 1, April 2011 dapat diklasifikasikan pemanfaatan dan maksud yang berbeda-beda (dalam Levin, Kirkpatrick, Rubin, 1982)

Sistem Informasi Akademik (SIA) di Universitas Bina Darma digunakan untuk mengolah data akademik, dari awal mahasiswa masuk sampai kelulusan mahasiswa. Sistem ini mencakup penerimaan mahasiswa baru, proses seleksi, proses perkuliahan, penjadualan kelas, sampai dengan proses pendafraran wisuda. Dosen dan mahasiswa dapat mengakses sistem ini untuk melihat data akademik mereka.

E-Learning adalah pembelajaran jarak jauh (distance Learning) yang memanfaatkan teknologi komputer, jaringan komputer dan internet. E-Learning memungkinkan pembelajar untuk belajar melalui komputer di tempat mereka masing-masing tanpa harus secara fisik pergi mengikuti pelajaran/perkuliahan di kelas. E-Learning sering pula dipahami sebagai suatu bentuk pembelajaran berbasis web yang bisa diakses dari intranet di jaringan lokal atau internet. Sebenarnya materi e-learning tidak harus didistribusikan secara on-line baik melalui jaringan lokal maupun internet. Universitas Bina Darma sendiri sudah lama menggunakan e-laerning yang berbasis LMS (Learning Management Service) Moodle. Moodle adalah open source Course Management Sytem (CMS) yang banyak digunakan universitas, komunitas, sekolah, bisnis dan bahkan instruktur individual untuk menambahan teknologi web kedalam kelas mereka. (J Cole, H Foster, 2007)

External Database merupakan sebuah fitur yang di LMS Moodle yang berguna untuk mensinkronkan data user dan enrolment dengan database di luar moodle. Dengan fitur ini moodle berkemampuan untuk membaca data dari database lain yang sudah di mapping di moodle. External Database terbagi jadi dua bagian yaitu External Database Authentication dan External Database Enrollment. (Elizabeth Hamel, 2008)

Universitas Bina Darma juga sudah membuat program untuk mengimport user, kelas, dosen, dan peserta kelas dari SIA ke e-learning yang berbasis moodle, yang biasaya di jalankan untuk mengimport data di awal semester. Akan tetapi timbul beberapa permasalahan dengan sitem import tersebut, yang pertama setiap kali ada perubahan stuktur data di SIA yang menyangkut tentang perkuliahan atau ada upgrade versi di elearningnya sendiri program tersebut harus di update karena harus menyesuaikan lagi dengan struktur data yang baru. Permasalahan yang kedua adalah ketika ada perubahan data dipertengahan semester seperti user merubah password, penggantian dosen mengajar, pengeditan krs mahasiswa harus dilakukan manual di kedua sisi, di SIA dan di e-learning. Hal itu disebabkan oleh adanya kehawatiran hilangnya data tugas atau materi yang telah diberikan dosen dan dikerjakan mahasiswa apablia melakukan import ulang dari program tersebut, karena program ini akan menghapus data yang ada di elaerning dan mengimport kembali data dari SIA ke E-Learning. Permasalahan lain yang timbul adalah menghilangnya semua data ketika elearning akan dipakai di semester selanjutnya, sehingga dosen harus membackup materi mereka secara manual sebelum semester berakhir.

Melihat dari permasalahan tersebut perlu diterapkannya fitur External Database untuk mensinkronkan data dari SIA ke E-Learning yang mampu mentransfer dan merubah data secara realtime dan tidak menghilangkan data data yang sudah di import di E-Learning sebelumya. Sehingga proses pengeditan manual di E-Learning apabila data sudah ter import bisa di hilangkan dan riwayat materi ajar dosen bisa di akses oleh dosen yang bersangkutan.

\section{METODOLOGI PENELITAN}

Metodologi Penelitian merupakan cara melakukan suatu dengan menggunakan pikiran secara seksama untuk mencapai suatu tujuan (Rosa dan Shalahuddin, 2015). 


\subsection{Metode Penelitian}

Pada penelitian ini metode penelitian yang digunakan adalah action research. Action research dikenal dengan berbagai nama lain, seperti partisipatory action research, collaborative inquiry, emansipatory research, dan contextural action research. Semua variasi istilah tersebut merupakan istilah lain atau dapat dikategorikan action research. Dalam lingkup penelitian kebijakan memang telah dikenal lama tentang model action research. Dilihat dari konteks praxis, model action research merupakan model penelitian yang sekaligus berpraktik dan berteori, atau menggabungkan teori sekaligus melaksanakan dalam praktik. Dalam Bahasa Indonesia Action Research diterjemahkan dengan "penelitian tindakan", namun ada juga yang menyebut dengan "kaji tindak". (J, Sarwono, 2006)

Desain penelitian tindakan adalah berotasi antara kegiatan rutin manajerial (M), mengadakan penelitian (R), dan mengembangkan teori (D). Secara berkelanjutan ketiganya dievaluasi (E). Action Research menjadi model alternatif untuk penelitian dalam kerangka berfikir praxis. (Noeng Muhadjir, 2000).

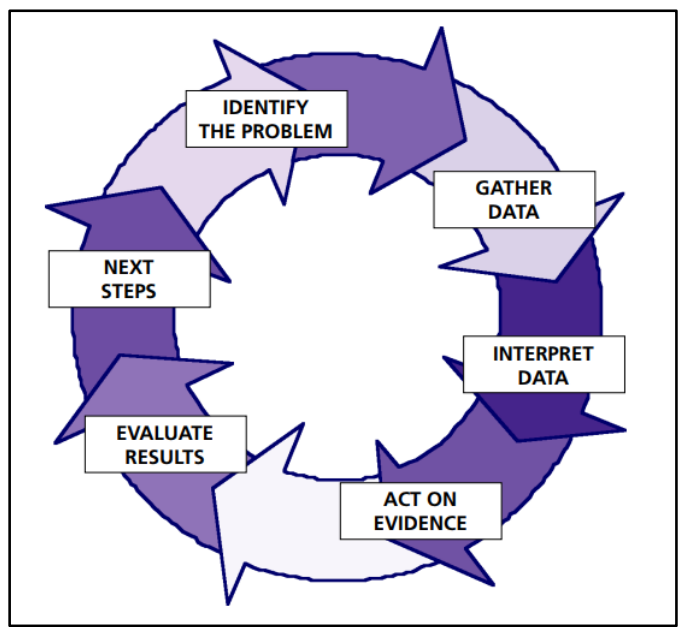

Gambar 1. Siklus Action Research

Adapun tahapan atau siklus dari metode eksperimen ialah sebagai berikut :

a. Rencana Tindakan, meliputi :
a. Refleksi awal
b. Perumusan masalah
c. Perumusan hipotesis (Jika ada)
d. Perumusan rancangan tindakan

b. Pelaksanaan Tindakan, meliputi:
a. Merancang intervensi
b. Melakukan kolaborasi
c. Pengamatan tindakan secara sadar, kritis dan objektif

c. Observasi, Reflesi dan Implikasi

\subsection{Metode Pengumpulan Data}

Metode pengumpulan data yang digunakan dalam melakukan penelitian ini :

1. Studi Kepustakaan (Literature)

Yaitu data yang diperoleh melalui literature, melakukan studi kepustakaan dalam mencari bahan dari internet dan membaca buku yang sesuai dengan objek yang akan diteliti ;

2. Penelitian (Observation)

Metode pengumpulan data dengan cara melakukan penelitian secara langsung pada objek penelitian yaitu pada Universitas Bina Darma, dengan mempelajari bagaimana Sistem Informasi Akademik dan E-Leraning selama ini berjalan. 


\section{HASIL DAN PEMBAHASAN}

\subsection{Integrasi Data User}

Integrasi data user merupakan proses untuk menghubungkan data user yang tersedia di Sistem Informasi Akademik (SIA) dangan E-Learning Moodle (WRice, 2015). Untuk melakukan integrasi ini peneliti menggunakan fitur External Database Authentication pada moodle dengan flow sebagai berikut.

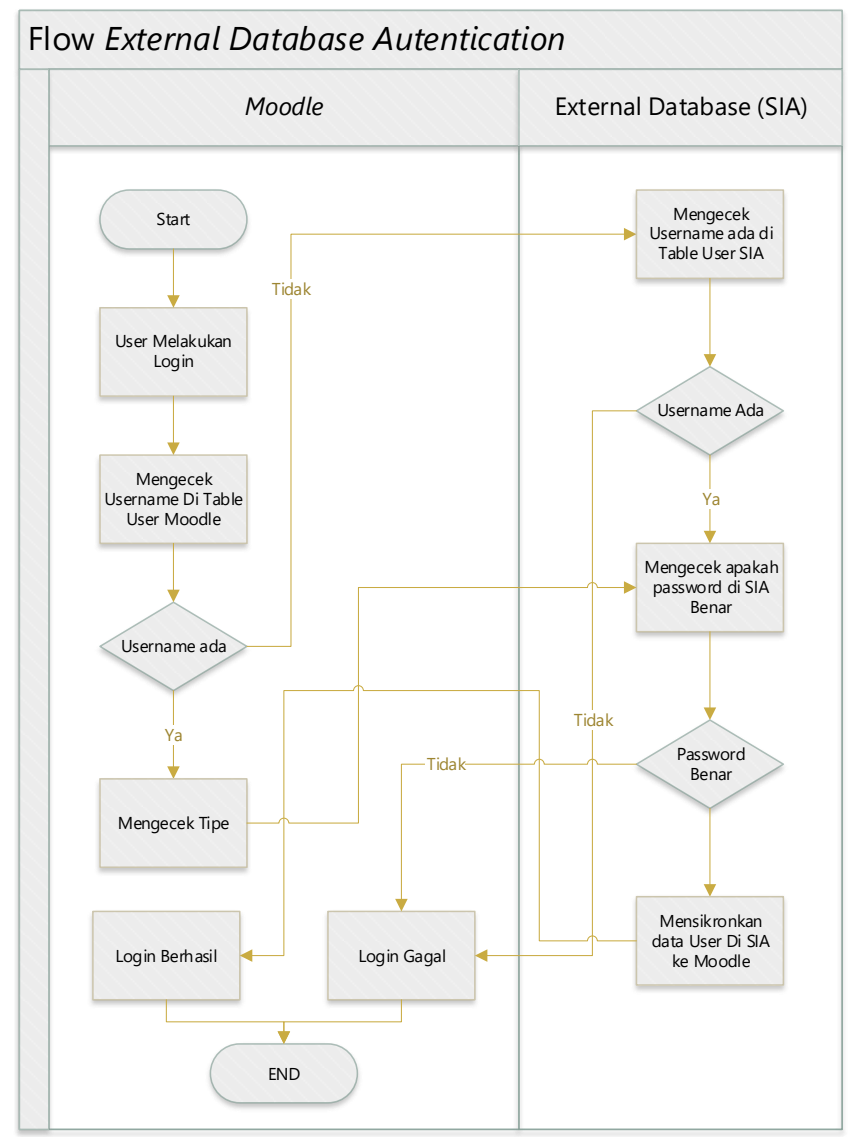

Gambar 2 Flow External Database Authentication

Untuk menerapakan External Database Authentication, diperlukan untuk melakukan tahap tahap dibawah ini:

1. Menyiapkan view di database SIA yang menyediakan data mahasiswa, dan dosen yang bisa login di E-Learning, beserta profil yang diperlukan oleh moodle berikut ini :

Tabel 1. Field External Database Auth

\begin{tabular}{|c|c|c|}
\hline & Field & Keterangan \\
\hline 1 & Userid & Index pada SIA \\
\hline 2 & UserCode & Username yang digunakan untuk login \\
\hline 3 & Fistname & Nama Awal \\
\hline 4 & Lastname & Nama Akhir \\
\hline 5 & UserPassword & Password SIA dengan enkripsi MD5 \\
\hline 6 & UserAddress & Alamat User \\
\hline 7 & Email & Email user \\
\hline
\end{tabular}


8 no_telp No Telp atau kontak user

2. Mengaktifkan fitur External Database Authantication, dapat dilakukan dengan cara login administrator moodle dan mangakses site administration >> plug in >> authentication >> manage authentication. Dan menyentang plugin external database authentication.

3. Melakukan setting database external pada plugin autentikasi dengan setingan seperti tabel 2 dibawah ini:

Tabel 2. Setting External DB Auth

\begin{tabular}{lll}
\hline \multicolumn{1}{c}{ Setting } & Value \\
\hline 1 & Host & IP Server DB SIA \\
2 & Database & mssqlnative \\
3 & Db Name & Nama Database SIA \\
4 & DB User & Username DB SIA \\
5 & Password & Password DB SIA \\
6 & Table & Moodle_UserMasterView \\
7 & Username field & UserCode \\
8 & Passowrd field & UserPassword \\
9 & Password format & MD5 hash \\
\hline
\end{tabular}

4. Melakukan Mapping di sistem moodle. Proses ini bertujuan untuk memetakan field yang sudah kita siapkan sebelumnya ke data yang harus dipenuhi di moodle. Dapat di dilakukan pada menu site administration > plug in > authentication >> external database. Ada 2 perlakuan update untuk mapping field external $d b$ yaitu On Login (Mengupdate table moodle setiap kali user login) dan On Creation (Mengupdaet table moodle hanya pada saat user pertama kali login)

Tabel 3. Mapping External DB Auth

\begin{tabular}{llll}
\hline & Field Moodle & \multicolumn{1}{c}{ Field SIA } & Update Local \\
\hline 1 & Firstname & Firstname & On Login \\
2 & Surname & Lastname & On Login \\
3 & Email & Email & On Login \\
4 & Address & UserAddress & On Login \\
5 & Idnumber & Userid & On Creation \\
6 & Phone & Nomor_hp & On Login \\
\hline
\end{tabular}

Proses integrasi user dilakukan setiap kali ada user yang melakukan login ke sistem, dengan demikian maka data user bisa di integrasikan secara real time selama moodle terkoneksi dengan database SIA.

\subsection{Integrasi Data Kelas}

Data kelas merupakan data matakuliah dan kelas yang dibuka pada semester tersebut. Di dalam elearning moodle data kelas ini ditampung pada data tabel course yang dikelompok kan berasarkan fakultas, program studi, dan tahun akademik agar mudah dalam melakukan pencarian course. Untuk melakukan integrasi data ini, penulis menggunakan fitur external database enrolment dengan langkah langkah sebagai berikut:

1. Menyiapkan course categories pada moodle dengan struktur seperti gambar 3 


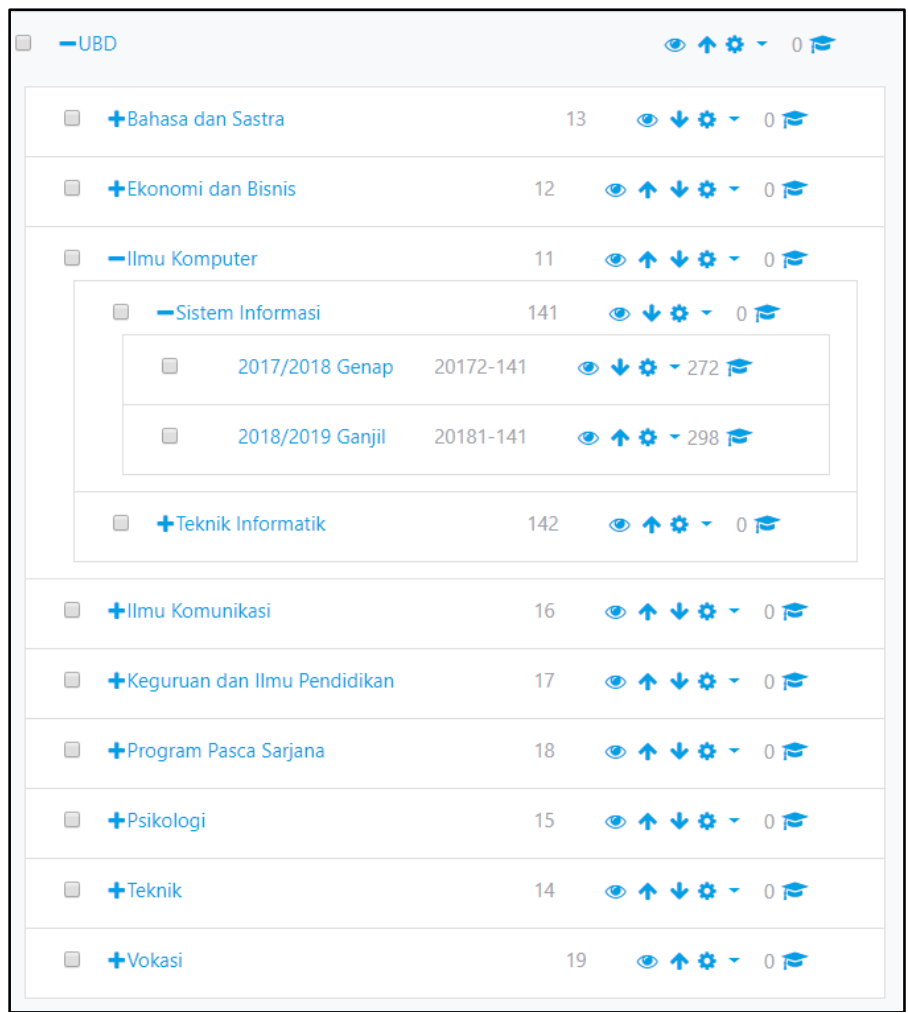

Gambar 3 Course Categories

Idnumber pada Course Categories dibuat dengan format (tahun_akademik-kode_prodi) contohnya (20181-141) agar ketika melakukan sinkronasi course langsung terkelompok secara otomatis.

2. Mengaktifkan fitur External Database Enrollment, dapat dilakukan dengan cara login administrator moodle dan mangakses site administration $\gg$ plug in > enrollment >> manage enrollment. Dan menyentang plugin external database enrollment.

3. Menyiapkan view pada database SIA untuk menampung data Course, dengan struktur seperti gambar 4

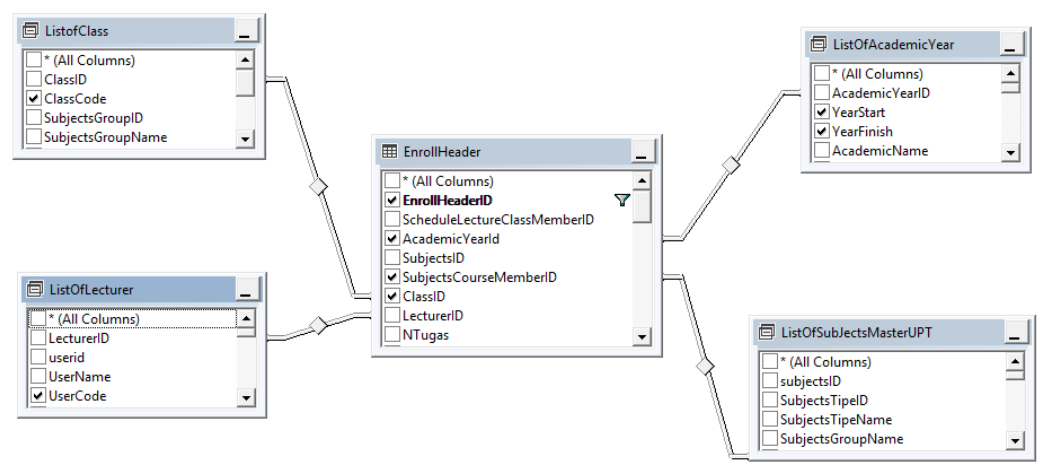

Gambar 4 View Course 
4. Melakukan setting external database enrolment dengan seting seperti table dibawah ini

Tabel 3. Setting External DB Enroll

\begin{tabular}{lll}
\hline \multicolumn{1}{c}{ Setting } & \multicolumn{1}{c}{ Value } \\
\hline 1 & DB Driver & Mssqlnative \\
2 & Host & IP DB SIA \\
3 & Dbuser & User DB SIA \\
4 & DBPassword & Password DB SIA \\
5 & Database & Nama Database SIA \\
6 & Remote new course table & MoodleCourseView \\
\hline
\end{tabular}

5. Melakukan mapping external database enrollment untuk bagian course. Dengan mapping seperti table dibawah ini

Tabel 4. Mapping External DB Auth

\begin{tabular}{lll}
\hline & \multicolumn{1}{c}{ Field Moodle } & \multicolumn{1}{c}{ Field SIA } \\
\hline 1 & Fullname & Coursename \\
2 & Sortname & Sortname \\
3 & Idnumber & EnrollHeaderID \\
4 & CourseCatagories & CourseCatagories \\
\hline
\end{tabular}

Didalam moodle integrasi data kelas didalam satu modul dengan integrasi data krs (Database Enrollment), jadi sebelum menjalankan nya harus menyelesaikan juga konfigurasi integrasi data peserta kelas.

\subsection{Integrasi Data Peserta Kelas.}

Data peserta kelas merupakan seluruh data mahasiswa yang ikut dalam kelas tersebut dan juga data dosen yang mengajar pada kelas tersebut. Integrasi ini dilakukan juga dengan fitur external database enrollment dengan langkah langkah sebagai berikut:

1. Menyiapkan tabel pada database SIA untuk menampung data enrollment sesuai kebutuhan Moodle. Hal ini dikarnakan struktur database SIA dipisahkan tabelnya antara pengajar dan mahasiswa ajar, sehingga perlu disatukan untuk dapat menggunakan fitur external database enrollment. Tabel tersebut mempunyai struktur seperti gambar dibawah ini:

\begin{tabular}{|c|c|c|}
\hline Column Name & Data Type & Allow Nulls \\
\hline EnrollHeaderID & int & $\square$ \\
\hline UserlD & int & $\square$ \\
\hline UserCode & nvarchar(50) & $\square$ \\
\hline RolelD & int & $\square$ \\
\hline AcademicYearID & int & $\square$ \\
\hline
\end{tabular}

Gambar 5 Table ElearningTableEnrollment

2. Membuat dan menjadwalkan store procedure yang mengisi table diatas agar dapat menggabungkan data mahasiswa ajar dan dosen pengajar serta menentukan role nya masing masing. 
3. Melakukan setting mapping untuk menentukan id penghunghubung antar tabel enrollment. Seting tersebut dilakukan seperti gambar dibawah ini

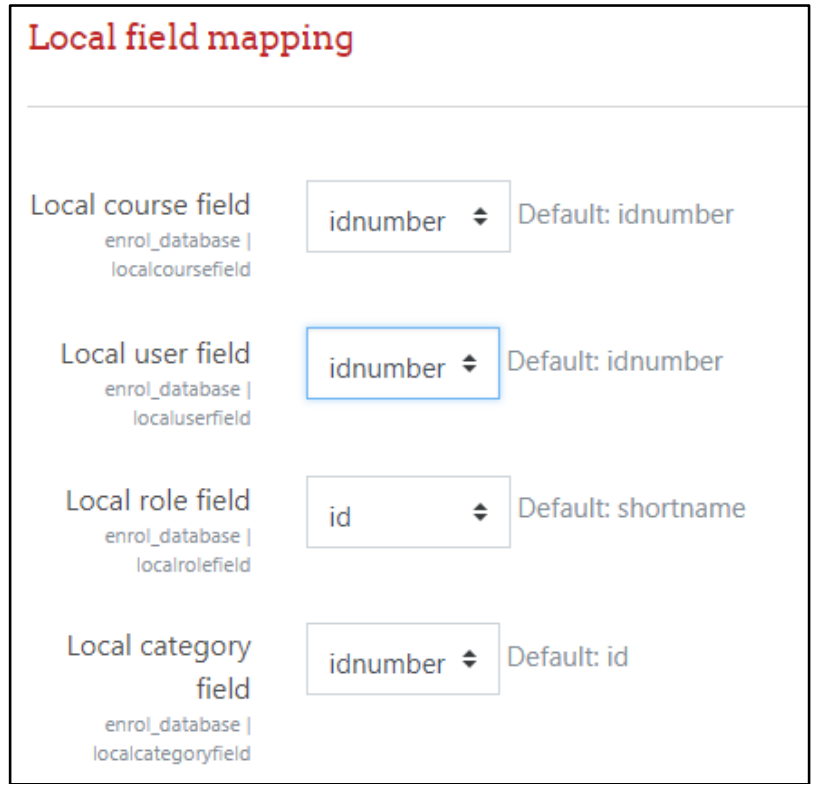

Gambar 5. Seting Local field mapping

4. Melakukan mapping external database enrollment untuk bagian enrollment. Dengan mapping seperti table dibawah ini

Tabel 4. Mapping External DB Auth

\begin{tabular}{lll}
\hline & \multicolumn{1}{c}{ Field Moodle } & \multicolumn{1}{c}{ Field SIA } \\
\hline 1 & CourseFiled & EnrollHeaderID \\
2 & User Filed & UserID \\
3 & RoleFiled & RoleID \\
\hline
\end{tabular}

5. Membuat cron job pada server untuk menjalankan perintah pada cmd "php (folder_moodle)/enrol/database/cli/sync.php". Cron Job ini dilakukan setiap 1 hari sekali untuk mengintegrasikan data course dan data enrollment dari SIA ke Moodle.

Proses integrasi course dan enrollment dilakukan 1 kali sehari pada malam hari, dikarnakan proses ini membutuhkan waktu yang cukup lama jadi tidak dilakukan secara terus menerus.

\section{KESIMPULAN dan SARAN}

\section{Kesimpulan}

Dari uraian-uraian diatas maka dapat di simpulkan bahwa penerapan External Database untuk mengintgrasikan data SIA dan E-learning dapat dilakukan dengan cara menyiapkan struktur data di SIA sesuai yang dibutuhkan oleh fitur External Datababase pada Moodle.

Fitur external database pada moodle terbagi jadi 2 bagian yaitu:

1. External database authentication, fitur ini berguna untuk mengintegrasikan data user dan password yang ada di database external (database SIA) 
2. External database enrollment, fitur ini gunanya untuk mengintegrasikan data kelas dengan data course pada moodle dan data peserta kelas dengan data enrollment pada moodle.

Untuk external database authentication proses integrasinya dilakukan setiap kali user melakukan login pada moodle, sehingga data bisa di integrasikan secara realtime, sedangkan untuk external database enrollment poses integrasinya dilakukan dengan cara mengeksekusi file yang telah disipakan dimoodle pada php cli dan juga memakan waktu yang cukup lama, oleh karna itu proses ini hanya dilakukan 1 hari 1 kali pada malam hari agar tidak membebani server, hal ini mengakibatkan perubahan data pada SIA untuk enrollment baru terintegrasi pada moodle ke esokan harinya.

\section{Saran}

Untuk penelitian selanjutnya integrasi antara SIA dan Elearning bisa diperluas lagi, tidak hanya sebatas Authentication dan Enrollmen saja, teteapi dapat diperluas integrasi nilai yang ada di elearning, dan juga untuk permasalahan integrasi Enrollment bisa di cari solusinya agar dapat terintegrasi secara realtime.

\section{Referensi}

AS. Rosa, dan Shalahuddin. 2015. Perangkat Lunak Terstruktur dan Berorientasi Objek. Informatika. Bandung.

Cole, J., \& Foster, H. (2007). Using Moodle: Teaching with the popular open source course management system. " O'Reilly Media, Inc.".

Hamel, Elizabeth B., and Bruce G. Lindsay. (2008) "Method for sequential coordination of external database application events with asynchronous internal database events." U.S. Patent.

Muhadjir, Noeng. 2000. Metode Penelitian Kualitatif edisi IV. Rake Sarasin. Yogyakarta.

Murdich, R.G., and Joel, R. 1982. Information System for Modern Management. 2nd Edition, Prentice Hall of India New Delhi.

Rice, W. (2015). Moodle e-learning course development. Packt Publishing Ltd.

Sarwono, J., Arikunto, M., \& Arikunto, M. S. (2006). Metode Penelitian. Kuantitatif Kualitatif. 